ISSN 0103-9954

\title{
FLORESTA OMBRÓFILA DENSA DE SANTA CATARINA - BRASIL: AGRUPAMENTO E ORDENAÇÃO BASEADOS EM AMOSTRAGEM SISTEMÁTICA
}

\author{
DENSE OMBROPHILOUS FOREST IN SANTA CATARINA - BRAZIL: CLUSTER ANALYSIS AND \\ ORDENATION BASED ON SYSTEMATIC SAMPLING
}

\author{
Débora Vanessa Lingner ${ }^{1}$ Lauri Amândio Schorn ${ }^{2}$ Lucia Sevegnani ${ }^{3}$ André Luís de Gasper ${ }^{4}$ \\ Leila Meyer ${ }^{5}$ Alexander Christian Vibrans ${ }^{2}$
}

\begin{abstract}
RESUMO
O presente trabalho teve por objetivo caracterizar os remanescentes da Floresta Ombrófila Densa, no estado de Santa Catarina. O conjunto de dados utilizado neste estudo foi disponibilizado pelo projeto Inventário Florístico Florestal de Santa Catarina, sendo oriundo de 197 unidades amostrais do tipo conglomerado. Os conglomerados foram constituídos por quatro subunidades de $20 \times 50 \mathrm{~m}$, nas quais foram mensurados todos os indivíduos arbóreo-arbustivos com DAP $\geq 10 \mathrm{~cm}$. A estrutura da floresta foi caracterizada com o emprego de parâmetros e índices fitossociológicos. Com base na densidade das espécies, foram realizadas análises de agrupamento e ordenação na tentativa de identificar grupos de bacias hidrográficas e faixas de altitude. Foram encontradas 577 espécies, pertencentes a 226 gêneros e 83 famílias. As famílias mais representativas em número de espécies e indivíduos foram Myrtaceae, Lauraceae e Fabaceae. Espécies de áreas perturbadas como Alchornea triplinervia, Caseria sylvestris e Miconia cinnamomifolia estão dentre as que dominam a floresta. Por meio da análise de agrupamento, foi possível identificar três formações ao longo do gradiente altitudinal, aqui denominadas: Floresta Ombrófila Densa de Terras Baixas $(<30 \mathrm{~m})$, Submontana $(30-500$ $\mathrm{m})$ e Montana ( $>500 \mathrm{~m}$ ). Variações florísticas e estruturais puderam ser detectadas entre as três formações. Em comunidades das terras baixas, a presença das famílias Anacardiaceae e Clusiaceae foi mais expressiva e a altura média das árvores foi superior. Nos ambientes montanos, observou-se um aumento no número de indivíduos, área basal e diversidade, além da maior representatividade das famílias Cyatheaceae, Lauraceae e Rubiaceae. A ocorrência de Arecaceae foi marcante nos patamares submontanos. Grupos espaciais não puderam ser seguramente definidos a partir de dados estruturais de bacias hidrográficas.

Palavras-chave: Floresta Atlântica; fitossociologia; padrões espaciais; gradiente altitudinal.
\end{abstract}

\section{ABSTRACT}

This study aimed to characterize the remnants of Ombrophilous Dense Forest in Santa Catarina state. The dataset used in this study was provided by Project of Floristic and Forest Inventory of Santa Catarina, coming from 197 sample units that consist of basic clusters. The basic cluster was composed of four

1 Engenheira Florestal, MSc., Departamento de Engenharia Florestal, Centro de Ciências Tecnológicas, Universidade Regional de Blumenau, Rua São Paulo, 3250, CEP 89030-000, Blumenau (SC), Brasil. deboravanessa.ef@gmail.com

2 Engenheiro Florestal, Dr., Professor do Departamento de Engenharia Florestal, Centro de Ciências Tecnológicas, Universidade Regional de Blumenau, Rua São Paulo, 3250, CEP 89030-000, Blumenau (SC), Brasil. lauri.schorn@gmail.com/acvibrans@gmail.com

3 Bióloga, Dr., Professora do Departamento de Ciências Naturais, Centro de Ciências Exatas e Naturais, Universidade Regional de Blumenau, Rua Antônio da Veiga, 170, CEP 89010-971, Blumenau (SC), Brasil. luciasevegnani@gmail.com

4 Biólogo, MSc., Professor do Departamento de Ciências Naturais, Centro de Ciências Exatas e Naturais, Universidade Regional de Blumenau, Rua Antônio da Veiga, 170, CEP 89010-971, Blumenau (SC), Brasil. algasper@gmail.com

5 Bióloga, Mestranda em Biologia Vegetal, Instituto de Ciências Biológicas, Universidade Federal de Minas Gerais, CEP 31270-901, Belo Horizonte (MG), Brasil. leilameyer08@gmail.com

Recebido para publicação em 5/07/2012 e aceito em 28/03/2014

Ci. Fl., v. 25, n. 4, out.-dez., 2015 
subunits of $20 \times 50 \mathrm{~m}$, in which all individuals with $\mathrm{DBH} \geq 10 \mathrm{~cm}$ were measured. The forest structure was characterized through phytosociological parameters and indices. Based on structural data of the species, cluster analysis and ordination were performed in an attempt to identify groups of watersheds and altitude ranges. It was identified 577 species belonging to 226 genera and 83 families. The most representative families in number of species and individuals were Myrtaceae, Lauraceae and Fabaceae. Species of disturbed areas as Alchornea triplinervia, Caseria sylvestris and Miconia cinnamomifolia were dominant in the forest. Cluster analysis resulted in the identification of three vegetation types along the altitudinal gradient: Lowland Ombrophilous Dense Forest (<30 m a.s.1.), Submontane (30 - $500 \mathrm{~m})$ and Montane ( $>$ $500 \mathrm{~m}$ ). Floristic and structural variations could be detected between the three vegetation types. In lowland communities, the presence of Anacardiaceae and Clusiaceae was more expressive and the average height of trees was higher. In montane environments, there was an increase in the number of individuals, basal area and diversity, as well as a greater representation of Cyatheaceae, Lauraceae and Rubiaceae. The occurrence of Arecaceae was remarkable in submontane forest. Spatial groups could not be defined based on structural data of watersheds.

Keywords: Atlantic Forest; phytosociology; spatial patterns; altitudinal gradient.

\section{INTRODUÇÃO}

A Floresta Ombrófila Densa, denominada também como Floresta Tropical Atlântica, é uma das regiões fitoecológicas inseridas no Bioma Mata Atlântica e constitui um prolongamento da faixa florestal que acompanha a costa brasileira desde o estado do Rio Grande do Norte até o estado do Rio Grande do Sul, distribuindo-se em um gradiente altitudinal que varia do nível do mar até aproximadamente 1.000 m (LEITE e KLEIN, 1990; IBGE, 1992) ou, conforme Siminski et al. (2011), até $500 \mathrm{~m}$.

Embora esteja situada em zona extratropical, a Floresta Ombrófila Densa possui características nitidamente tropicais, sendo marcada pela ausência de um período seco, com elevadas taxas de precipitação bem distribuídas ao longo do ano e temperaturas médias acima de $15^{\circ} \mathrm{C}$ (NIMER, 1979; LEITE e KLEIN, 1990; IBGE, 1992).

$\mathrm{Na}$ Floresta Ombrófila Densa ocorrem diferentes formações, correspondentes às variações naestrutura dascomunidades, resultantes da interação entre fatores físicos, como diferentes feições geológicas, pedológicas e altitude (IBGE, 1992). No estado de Santa Catarina, Klein (1978) subdividiu esta região fitoecológica em oito formações distintas, em função de suas espécies características. A despeito destas variações, alguns aspectos são comuns a todas as formações da Floresta Ombrófila Densa, sendo florestas sempre verdes (perenifólias), cujas espécies comumente apresentam folhas largas (latifoliadas) e se desenvolvem em ambientes muito úmidos (ombrófilas) (FERNANDES, 2003).
Conforme Leite e Klein (1990), em geral, a Floresta Ombrófila Densa caracteriza-se também por estratos superiores com árvores de altura entre 25 e $30 \mathrm{~m}$ e com as suas copas entrelaçadas, portando brotos foliares desprovidos de proteção à seca e às baixas temperaturas.

A Floresta Ombrófila Densa cobria originalmente $29.309 \mathrm{~km}^{2}$ de superfície (KLEIN, 1978), correspondendo a quase $31 \%$ do território do estado de Santa Catarina. Conforme Vibrans et al. (2012), encontram-se atualmente $16.821 \mathrm{~km}^{2}$ de remanescentes florestais, em sua maioria em estágio secundário de regeneração, o que equivale a $55,42 \%$ da cobertura original. A substituição das comunidades vegetais autóctones por sistemas agropecuários, áreas urbanas e industriais é um dos fatores que ameaçam a manutenção da floresta e de sua biodiversidade. O extrativismo vegetal predatório tem ocasionado desequilíbrios significativos nas populações de algumas espécies exaustivamente exploradas e consequente redução de sua base genética (PIRES et al., 2005).

Por outro lado, apesar de expressivamente fragmentada e alterada, a Floresta Ombrófila Densa ainda detém uma extraordinária complexidade biológica. Segundo Rochelle (2008) e Barros (1998), este fato oferece uma oportunidade ímpar para a realização de pesquisas sobre as condições atuais da floresta que possam gerar argumentos sólidos, visando à conservação dos remanescentes florestais e à manutenção da biodiversidade.

O presente trabalho teve por objetivo caracterizar a estrutura do componente arbóreoarbustivo da Floresta Ombrófila Densa e distinguir 
grupos florístico-estruturais, identificando as variações fisionômicas existentes entre os mesmos.

\section{MATERIAL E MÉTODOS}

\section{Área de estudo}

A área de estudo corresponde à região de ocorrência da Floresta Ombrófila Densa no estado de Santa Catarina, delimitada segundo o mapeamento de Klein (1978) (Figura 1). Esta região fitoecológica encontra-se entre as coordenadas geográficas $25^{\circ} 57^{\prime} 40^{\prime \prime}$ e $29^{\circ} 19^{\prime} 13^{\prime \prime}$ de latitude sul e $48^{\circ} 24^{\prime} 21^{\prime \prime}$ e $50^{\circ} 14^{\prime} 14^{\prime \prime}$ de longitude oeste.

\section{Obtenção dos Dados}

Os dados foram coletados em 197 remanescentes florestais (Figura 1), através do método de área fixa, perfazendo uma área total amostrada de 70,18 ha. As unidades amostrais foram implantadas de forma sistemática e sua distribuição foi definida pelo cruzamento de uma grade de pontos com distância entre si de $10 \mathrm{x}$ $10 \mathrm{~km}$ com o mapeamento dos remanescentes florestais (SAR, 2005). Nos pontos que incidiram sobre um remanescente florestal foram implantadas unidades amostrais em forma de conglomerado. Este é composto por quatro braços (subunidades) dimensionados em 20 × 50 m, orientados na direção dos quatro pontos cardeais (norte, sul, leste e oeste), conferindo à unidade amostral uma área total de amostragem de $4.000 \mathrm{~m}^{2}$. Foram medidos todos os indivíduos com diâmetro a altura do peito (DAP) igual ou superior a $10 \mathrm{~cm}$ (VIBRANS et al., 2010).

\section{Caracterização da floresta}

A estrutura do componente arbóreoarbustivo foi analisada através dos parâmetros fitossociológicos (densidade, dominância, frequência e valor de importância), conforme proposto por Müeller-Dombois e Ellenberg (1974).

Para expressar a diversidade da composição florística foram aplicados o Índice de Diversidade de Shannon-Wiener (H') e o Índice de Equabilidade de Pielou (J) (BROWER e ZAR, 1984).

\section{Definição dos grupos florístico-estruturais}

Buscando-se detectar grupos distintos na Floresta Ombrófila Densa em Santa Catarina, aplicou-se a técnica de agrupamento hierárquico em duas situações relacionadas aos aspectos geográficos, envolvendo a altimetria e bacias hidrográficas.

Para avaliar o aspecto da altimetria por meio da análise de agrupamento, as unidades amostrais foram distribuídas em 10 classes de altitude (Tabela 1). As unidades amostrais foram

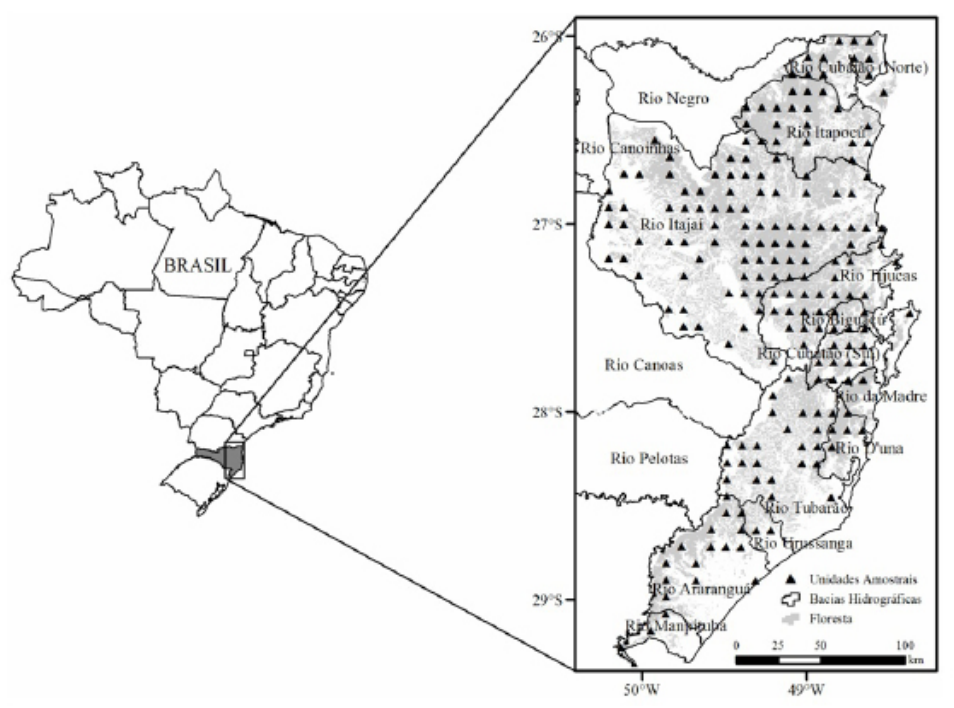

FIGURA 1: Unidades amostrais implantadas na região de ocorrência da Floresta Ombrófila Densa no estado de Santa Catarina, sul do Brasil.

FIGURE 1: Sample units in the region of occurrence of the Ombrophilous Dense Forest in the state of Santa Catarina, southern Brazil. 
enquadradas também nas 12 bacias hidrográficas (Tabela 1) existentes na região de ocorrência da Floresta Ombrófila Densa (SDM, 1997) em Santa Catarina. A única unidade amostral locada na bacia hidrográfica do rio da Madre foi contabilizada junto com as do rio Cubatão Sul, devido à proximidade e semelhanças entre as duas bacias, resultando, portanto, em 11 bacias hidrográficas analisadas no presente estudo.

Matrizes de dados foram construídas com as linhas sendo representadas pelas espécies e as colunas, pelos casos descritos (altitude ou bacias hidrográficas). Cada célula da matriz foi preenchida pelo valor da densidade média das $i$ espécies em cada classe de altitude ou bacia hidrográfica. As espécies com valor médio de densidade inferior a 1 ind.ha ${ }^{-1}$ foram eliminadas das matrizes, pois, conforme Gauch (1982), as espécies raras influem de maneira pouco significativa nos resultados do agrupamento.

O método de Ward ou de mínima variância foi aplicado na análise de agrupamento, o qual, segundo Valentin (2000) e Blum (2006), é uma das técnicas mais adequadas em análises de vegetação que utilizam grandes matrizes com dados heterogêneos. O número dos grupos homogêneos foi definido aplicando-se a linha fenon paralelamente ao eixo horizontal do dendrograma de agrupamento (SOUZA et al., 1990; MEDEIROS, 2008; SILVA, 2009), tracejando-a na metade do maior valor da distância euclidiana observado no dendrograma. A eficiência de cada método de agrupamento hierárquico foi avaliada através do coeficiente de correlação cofenética $(\mathrm{Ccc})$, conforme procedimento adotado por Barros (1998) e Bezerra Neto et al. (2010).
Utilizando as mesmas matrizes, também foi realizada a ordenação dos dados através da Análise de Correspondência Retificada (DCA), que é uma técnica capaz de corrigir o efeito ferradura, melhorando o resultado das análises (HILL e GAUCH, 1980). As análises de agrupamento e ordenação foram efetuadas no software Past (HAMMER et al., 2001).

As espécies características de cada grupo foram descriminadas através da análise de espécies indicadoras - ISA (DUFRÊNE E LEGENDRE, 1997), utilizando o software PC-ORD 6.0 (MCCUNE e MEFFORD, 2011). Esta análise fornece um valor indicativo para cada espécie, calculado com base na abundância e frequência.

As médias dos descritores estruturais foram comparadas entre os grupos encontrados através da análise de variância (ANOVA) seguida por teste de médias de Tukey-Kramer, com nível de significância de $95 \%$. A análise estatística foi processada por meio do software estatístico BioEstat 5.0 (AYRES et al., 2007).

\section{RESULTADOS E DISCUSSÃO}

\section{Composição Florística}

Na Floresta Ombrófila Densa de Santa Catarina foram identificadas 577 espécies, reunidas em 226 gêneros e 83 famílias. Também foram encontradas 10 espécies exóticas, sendo: Citrus reticulata Blanco (dois indivíduos), Citrus x limon (L.) Osbeck (oito), Eriobotrya japonica (Thunb.) Lindl. (três), Eucalyptus sp. (25), Hovenia dulcis Thunb. (103), Magnolia champaca (L.) Baill. ex Pierre (três), Morus nigra L. (dois), Persea

TABELA 1: Número de unidades amostrais de cada faixa de altitude e bacia hidrográfica inserida na área de ocorrência da Floresta Ombrófila Densa em Santa Catarina, sul do Brasil.

TABLE 1: Number of sample units of each altitude range and watershed located in the area of occurrence of the Ombrophilous Dense Forest, in Santa Catarina, southern Brazil.

\begin{tabular}{ccccccccc}
\hline $\begin{array}{c}\text { Classe de } \\
\text { Altitude }(\mathrm{m})\end{array}$ & \multirow{2}{*}{ UA } & $\begin{array}{c}\text { Classe de } \\
\text { Altitude }(\mathrm{m})\end{array}$ & \multirow{2}{*}{ UA } & & Bacia Hidrográfica & UA & Bacia Hidrográfica & UA \\
\cline { 1 - 2 } $0-30$ & 11 & $401-500$ & 22 & & Rio Cubatão Norte & 12 & Rio Tijucas & 21 \\
$30-100$ & 19 & $501-600$ & 16 & Rio Itapocú & 19 & Rio D’Una & 5 \\
$101-200$ & 19 & $601-700$ & 23 & Rio Biguaçú & 4 & Rio Araranguá & 15 \\
$201-300$ & 26 & $701-800$ & 17 & Rio Cubatão Sul & 11 & Rio Manpituba & 3 \\
$301-400$ & 22 & $>800$ & 23 & Rio da Madre & 1 & Rio Urussanga & 2 \\
\hline
\end{tabular}

Em que: $\mathrm{UA}=$ número de unidades amostrais. 
americana Mill. (um), Pinus sp. (71) e Psidium guajava L. (dois).

Entre as espécies encontradas, seis são consideradas ameaçadas de extinção de acordo com MMA (2008): Araucaria angustifolia (Bertol.) Kuntze (um indivíduo), Euterpe edulis Mart. (1.511), Ocotea catharinensis Mez (411), Ocotea nectandrifolia Mez (117), Ocotea odorifera (Vell.) Rohwer (299) e Ocotea porosa (Nees \& Mart.) Barroso (52). Segundo Quinet e Andreata (2002), o que tem posto em risco a preservação das espécies de Lauraceae é a intensa exploração pela qual estas foram submetidas ao longo de muitos anos, devido ao alto valor de sua madeira e, no caso da Ocotea odorifera, seus óleos essenciais. Para Euterpe edulis, o extrativismo irregular e indiscriminado, o que leva à falta de manutenção de um banco de plântulas adequado, ocasionou uma drástica redução de suas populações (REIS et al., 1996). Araucaria angustifolia é típica da Floresta Ombrófila Mista (VIBRANS et al., 2011), sendo pouco registrada na Floresta Ombrófila Densa, o que explica seu baixo número de indivíduos.

As famílias com maior riqueza de espécies (Tabela 2) foram Myrtaceae (119 espécies), Fabaceae (55), Lauraceae (49), Melastomataceae (33) e Asteraceae (20). Estas famílias abrangeram 47,8\% do total de espécies encontradas no levantamento e são também descritas como as mais importantes da Floresta Ombrófila Densa no Brasil (OLIVEIRA-
FILHO e FONTES, 2000; FORZZA et al., 2010). Foram verificadas 52 famílias com apenas uma a três espécies.

As famílias mais abundantes foram Lauraceae (5.629 indivíduos), Cyatheaceae (4.755), Myrtaceae (3.398), Rubiaceae (2.592) e Euphorbiaceae (2.493), somando 39,3\% dos indivíduos (Tabela 2). Estas famílias também ocorreram em mais de $90 \%$ das unidades amostrais implantadas, com exceção da Cyatheaceae (82\%). Em florestas tropicais pluviais, conforme Souza et al. (2002), é comum que poucas famílias detenham grande número de indivíduos.

Os gêneros com maior número de espécies (Tabela 2) foram Eugenia (39 espécies), Myrcia (27), Ocotea (26), Miconia (17) e Myrcengenia (15), os quais englobaram $21,5 \%$ do total de espécies registradas. Estes gêneros detêm a maior riqueza de espécies na Floresta Atlântica e em Florestas Semidecíduas do Sudeste do país (OLIVEIRAFILHO e FONTES, 2000), com exceção de Myrceugenia. De acordo com Sobral (2003) e Landrum (1981), Santa Catarina é um dos centros de endemismo para Myrceugenia. Oliveira-Filho e Fontes (2000) elencaram ainda Mollinedia, Inga, Tibouchina, Erythroxylum, Marlieria e Pouteria dentre os gêneros com maior número de espécies da Floresta Atlântica. Mollinedia é típica de subbosque (PEIXOTO et al., 2001), por isso foi pouco amostrada no componente arbóreo-arbustivo.

TABELA 2: Síntese da diversidade de famílias, gêneros e espécies do componente arbóreo-arbustivo da Floresta Ombrófila Densa, em Santa Catarina.

TABLE 2: Synthesis of families, genera and species diversity recorded in the tree/shrub component of Ombrophilous Dense Forest in Southern Brazilian State of Santa Catarina.

\begin{tabular}{|c|c|c|c|c|c|c|}
\hline Famílias & Spp. & Gen. & Ind. & Gêneros & Spp. & Ind. \\
\hline Myrtaceae & 119 & 14 & 3398 & Eugenia & 39 & 566 \\
\hline Fabaceae & 55 & 28 & 2350 & Myrcia & 27 & 1595 \\
\hline Lauraceae & 49 & 9 & 5629 & Ocotea & 26 & 2847 \\
\hline Melastomataceae & 33 & 5 & 1654 & Miconia & 17 & 1295 \\
\hline Asteraceae & 20 & 9 & 1397 & Myrceugenia & 15 & 146 \\
\hline Rubiaceae & 19 & 14 & 2592 & Myrsine & 11 & 945 \\
\hline Euphorbiaceae & 16 & 10 & 2493 & Solanum & 11 & 318 \\
\hline Solanaceae & 16 & 5 & 450 & Inga & 10 & 519 \\
\hline Primulaceae & 13 & 3 & 964 & Symplocos & 10 & 155 \\
\hline Moraceae & 13 & 4 & 659 & Calyptranthes & 9 & 338 \\
\hline \multicolumn{4}{|c|}{ - 21 Famílias com 4 a 10 spp. } & \multicolumn{3}{|c|}{ - 27 Gêneros com 4 a 9 spp. } \\
\hline \multicolumn{4}{|c|}{ - 24 Famílias com 2 e 3 spp. } & \multicolumn{3}{|c|}{ - 47 Gêneros com 2 e 3 spp. } \\
\hline \multicolumn{4}{|c|}{ - 28 Famílias com uma espécie } & \multicolumn{3}{|c|}{ - 142 Gêneros com uma espécie } \\
\hline
\end{tabular}

Em que: Spp. = número de espécies; Gen. = número de gêneros; Ind. = número de indivíduos. 
Erytroxyllum e Pouteria possuem poucas espécies em Santa Catarina (REITZ, 1968; AMARAL JR., 1980).

\section{Grupos florístico-estruturais}

O dendrograma gerado para as bacias hidrográficas (Figura 2a) resultou em agrupamentos pouco consistentes, impossibilitando a detecção de padrões espaciais lógicos na região de ocorrência da Floresta Ombrófila Densa. No entanto, algumas tendências puderam ser inferidas, com no caso das bacias hidrográficas do extremo sul catarinense (Araranguá, Manpituba e Urussanga) que demonstraram ser bastante similares. Distinguiramse ainda, alguns pares de bacias hidrográficas com alta homogeneidade, a saber: Cubatão Sul e D'Una, Itajaí e Tijucas e Itapocú e Cubatão Norte.

A tentativa de estabelecer grupos estruturais ao longo do gradiente altitudinal forneceu resultados mais conclusivos, constatando-se a divisão das faixas de altitude em três grupos (Figura $2 b$ ). O nível mais baixo, $0-30 \mathrm{~m}$, mostra-se bastante dissimilar aos demais pisos altitudinais, constituindo um grupo isolado. Nota-se que na sequência, os pares $30-100$ $\mathrm{m} / 101-200 \mathrm{~m}$ e $301-400 \mathrm{~m} / 401-500$ m são relativamente similares, constituindo um segundo grupo. Os quatro níveis mais elevados formaram um terceiro grupo, no qual as faixas $501-600 \mathrm{~m}$ e $601-700 \mathrm{~m}$ e também $701-800 \mathrm{~m}$ e $>800 \mathrm{~m}$, formaram pares com estrutura bastante homogênea.

A Análise de Correspondência Retificada (DCA) demonstrou a segregação do conjunto de unidades amostrais em função da variação da altitude (Figura 3a), apesar dos dois primeiros eixos da ordenação representarem apenas 7,7\% e 5,8\% da variância total, respectivamente, com autovalores de 0,52 para o eixo 1 e 0,39 para o eixo 2 . A baixa variância de dados explicada pelos primeiros eixos é esperada para florestas heterogêneas (CATHARINO et al., 2006) ou pode-se supor ainda, que a variância não explicada estivesse relacionada a outras variáveis não incluídas nesta análise que poderiam influenciar nos padrões estruturais da floresta (CARVALHO et al., 2000). Com os escores das espécies plotados no gráfico, identifica-se aquelas associadas às faixas de altitude segregadas na ordenação (Figura 3b).

A avaliação conjunta dos resultados obtidos através das análises de agrupamento e ordenação permitiu a definição de três formações e seus respectivos limites altimétricos: (1) Floresta Ombrófila Densa de Terras Baixas - abaixo dos 30 m s.n.m.; (2) Floresta Ombrófila Densa Submontana - entre 30 e 500 m s.n.m.; (3) Floresta Ombrófila Densa Montana - acima dos 500 m s.n.m.

\section{Caracterização das formações}

Na Floresta Ombrófila Densa de Terras Baixas foi observada a menor diversidade $\left(\mathrm{H}^{\prime}=4,14\right.$ nats/ind e $\mathrm{J}=0,79$ ) com 183 espécies e 52 famílias. Em seguida, a Floresta Ombrófila Densa Montana $\left(H^{\prime}=4,97\right.$ nats/ind $\left.\mathrm{J}=0,79\right)$ apresentou 451 espécies e 79 famílias, incluindo áreas em transição com a Floresta Ombrófila Mista, registrando-se, por isso, a ocorrência de espécies como Araucaria angustifolia, Lithrea brasiliensis, Matayba elaeagnoides, Ocotea pulchella e Podocarpus lambertii. Caracterizada pela maior riqueza com 476 espécies e 78 famílias, a formação Floresta Ombrófila Densa Submontana $\left(\mathrm{H}^{\prime}=4,81\right.$ nats/ind e $\left.\mathrm{J}=0,77\right)$, por representar a classe intermediária entre as outras duas formações, abrange espécies de ambas, o que explicaria em parte, a maior diversidade registrada. A maior área amostral nesta formação também pode ter contribuído com tal diversidade.

As famílias mais representativas quanto à riqueza de espécies foram praticamente as mesmas em todas as formações, embora a ordem de classificação das famílias tenha variado (Figura 4a). Com base em sete levantamentos florísticos realizados na Floresta Atlântica de encosta no estado de São Paulo, Mantovani e Tabarelli (1999) constataram que grande parte da riqueza de espécies dos patamares submontanos e montanos se deve à contribuição de espécies de Myrtaceae, Fabaceae, Rubiaceae, Lauraceae, Melastomataceae, Euphorbiaceae e Sapotaceae, corroborando com os resultados do presente estudo.

No entanto, verificou-se a ausência de Asteraceae e a baixa densidade de Solanaceae na Floresta Ombrófila Densa de Terras Baixas, enquanto que nas florestas de maior altitude, estas famílias assumiram maior riqueza de espécies, conforme apontado também por Carvalho et al. (2008). A ausência ou o baixo número de indivíduos destas famílias foi constatado em algumas florestas de planície (GUEDES-BRUNI et al., 2006; PAULA, 2006; ZACARIAS, 2008).

Destaca-se também que Myrtaceae foi a família mais importante em todas as formações. Oliveira-Filho e Fontes (2000) afirmam que em diversas formações vegetacionais da Floresta Atlântica, Myrtaceae ocorre com a maior riqueza 
(a)

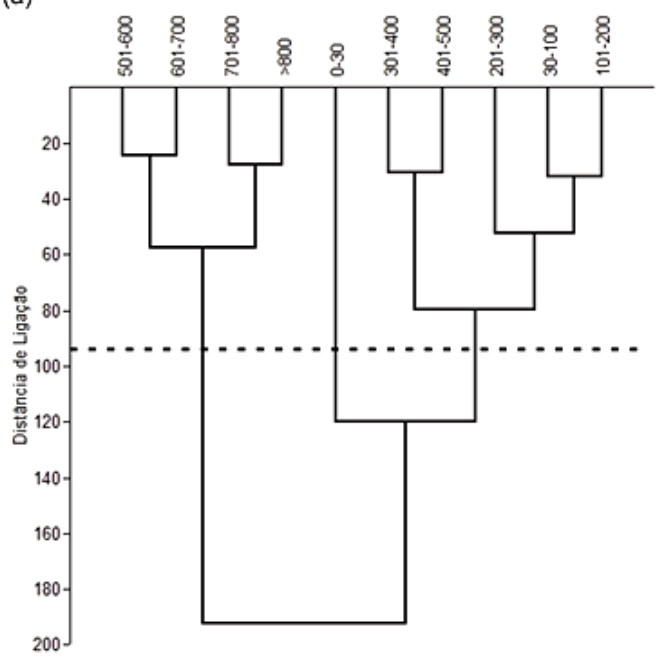

(b)

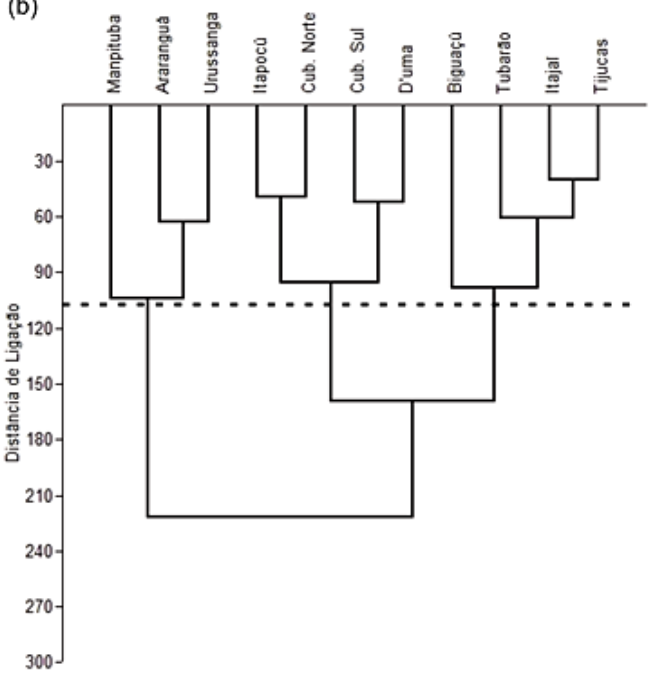

FIGURA 2: Dendrogramas de similaridade, a partir do método de Ward, com o agrupamento das (a) faixas de altitude $(\mathrm{Ccc}=0,76)$ e das $(\mathrm{b})$ bacias hidrográficas $(\mathrm{Ccc}=0,60)$, gerados com base na média da densidade das 139 espécies mais abundantes da Floresta Ombrófila Densa, em Santa Catarina, sul do Brasil. A linha tracejada representa a linha fenon (metade da maior distância euclidiana).

FIGURE 2: Dendrograms of similarity with the clustering of the (a) altitude ranges $(\mathrm{Ccc}=0.76)$ and $(\mathrm{b})$ watershed $(\mathrm{Ccc}=0.6)$, generated based on the average density of the 139 most abundant species of the Ombrophilous Dense Forest in Santa Catarina, southern Brazil. Dashed line fenon (half the largest euclidean distance).
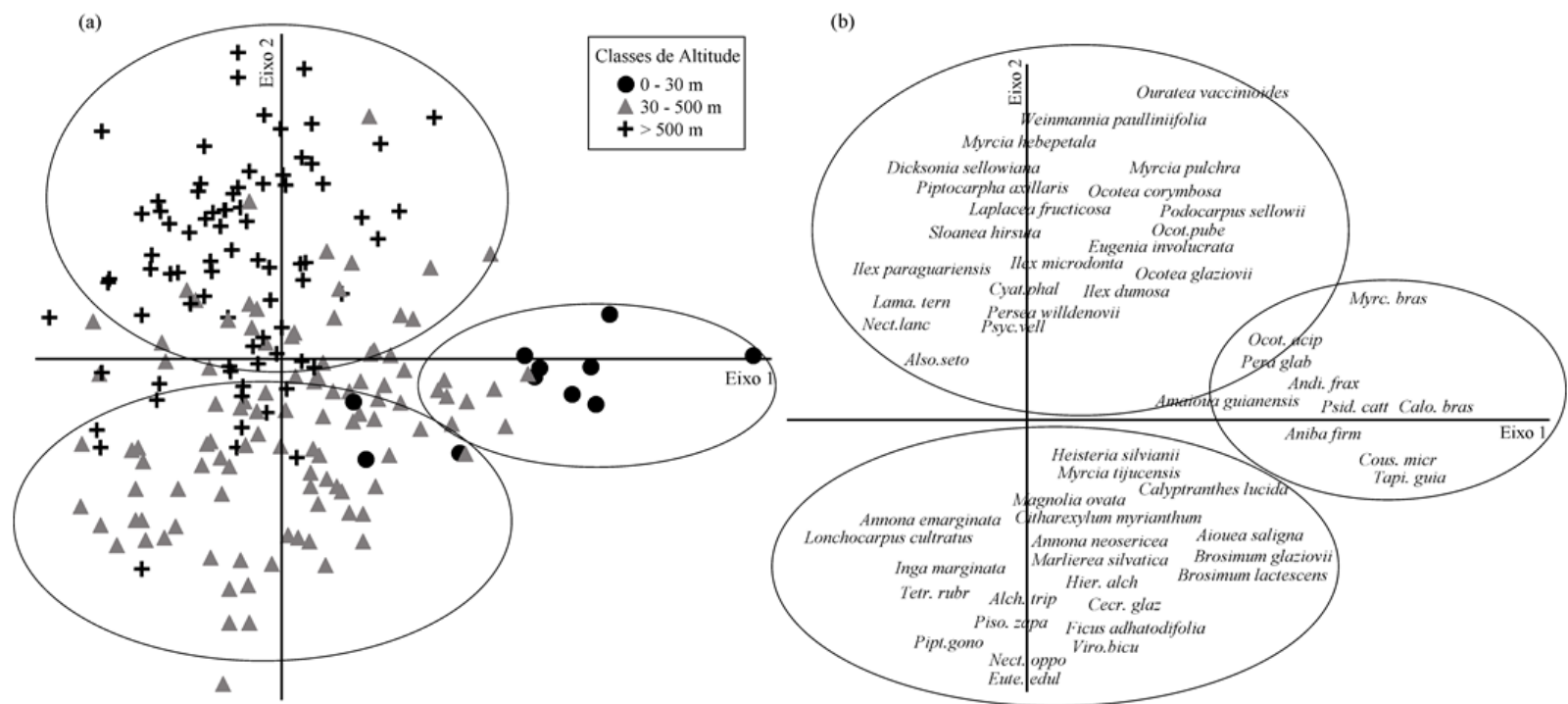

FIGURA 3: Ordenação dos dados da Floresta Ombrófila Densa, em Santa Catarina, por faixa de altitude, efetuada através da Análise de Correspondência Retificada (DCA), utilizando dados de densidade de 197 unidades amostrais e 139 espécies. Os diagramas mostram a ordenação das: a) unidades amostrais e b) espécies associadas nos Eixos 1 e 2.

FIGURE 3: Ordination of data from the Ombrophilous Dense Forest, in Santa Catarina, for altitude range, through Detrended Correspondence Analysis (DCA), using density data of 197 sample units and 139 species. The diagrams show the ordering of a) sample units and b) associated species on Axes 1 and 2. 
florística. Na Reserva Volta Velha - SC, em uma floresta de terras baixas, a alta diversidade de Myrtaceae foi registrada em todos os compartimentos amostrados, considerando plântulas, jovens e adultos (NEGRELLE, 2006). Segundo Mori et al. (1983), o litoral brasileiro é a única área neotropical onde esta família torna-se importante também nas florestas de planície. Em outras florestas neotropicais ocorre o predomínio da Fabaceae como na comunidade submontana do Parque Estadual da Serra do Tiririca - RJ (BARROS, 1998); e em um trecho de Floresta Ombrófila Densa Montana do município de São Luiz do Paraitinga - SP (AGUIRRE, 2008). Muitas espécies de Fabaceae possuem capacidade de fixar nitrogênio e é bem provável que, por esse motivo, consigam se estabelecer tão bem, mesmo em locais com baixas condições de fertilidade (CERVI et al., 2007).

Variações estruturais ainda mais nítidas ao longo do gradiente altitudinal podem ser constatadas quando apontadas as famílias mais representativas em número de indivíduos (Figura 4b). Em altitudes inferiores a $30 \mathrm{~m}$, as famílias Anacardiaceae e Clusiaceae estão entre as principais famílias. Por outro lado, sua ocorrência tende a ser menos expressiva com o aumento da altitude, especialmente da Anacardiaceae, representada majoritariamente por Tapirira guianensis, cujo número de indivíduos é bastante reduzido a partir de $500 \mathrm{~m}$. Em comunidades florestais do município de Ubatuba - SP, Lacerda (2001) apontou Myrtaceae, Arecaceae, Bignoniaceae, Meliaceae, Clusiaceae e Euphorbiaceae como os elementos diferenciadores das florestas de planície. Na Floresta Ombrófila Densa Submontana destaca-se Arecaceae como a segunda família mais abundante, com densidade de 49,7 ind.ha ${ }^{-1}$. Este fato deve-se, sobretudo, à Euterpe edulis, bem como de Syagrus romanzofianna, que são pouco abundantes em altitudes superiores a $500 \mathrm{~m}$. Lacerda (2001) observou que Arecaceae encontrava-se entre as principais famílias de todas as cotas altitudinais avaliadas, exceto na formação Montana $(1.000 \mathrm{~m})$. Na Floresta Ombrófila Densa Montana verificou-se um aumento da representatividade de Lauraceae e Rubiaceae, fato observado também por Lacerda (2001). Cyatheaceae destacou-se nesta formação como a família mais representativa, devido à elevada abundância da Alsophila setosa e espécies do gênero Cyathea. Alsophila setosa é caracterizada como espécie seletiva higrófita no norte do Estado do Rio Grande do Sul e sul de Santa Catarina (VELOSO e
KLEIN, 1968b), ocorrendo entre 20 e $1.800 \mathrm{~m}$ de altitude (FERNANDES, 1997), o que sugere que a altitude não é o fator limitante da distribuição da Cyatheaceae.

Observando as 20 espécies com maior valor de importância de cada formação (Tabela 4), nota-se que algumas delas são comuns e demonstram maior plasticidade. Blum e Roderjan (2007) ressaltam que as espécies de maior valor fitossociológico normalmente se adaptam melhor a uma gama mais ampla de situações ambientais. No entanto, mesmo sendo aptas a ocorrer ao longo de uma maior amplitude altimétrica, algumas espécies possuem faixas de altitude preferenciais. As espécies Tapirira guianensis, Nectandra oppositifolia e Pera glabrata mostram-se mais adaptadas às áreas com altitudes mais baixas, enquanto que Alsophila setosa, Psychotria vellosiana e Clethra scabra passam a ser mais bem representadas nos patamares montanos. Constata-se também que Syagrus romanzoffiana e Sloanea guianensis se adaptam melhor nas formações Submontana e de Terras Baixas e a presença de Cabralea canjerana, Guapira opposita e Bathysa australis torna-se mais expressiva a partir de $30 \mathrm{~m}$. De acordo com Cervi et al. (2007), Cabralea canjerana não possui preferência quanto à umidade do solo e é típica de ambientes com altitude mais elevada.

Atendo-se ainda apenas à relação das 20 espécies mais importantes, nota-se que 13 apareceram somente na formação de Terras Baixas, sete na Submontana e 13 na Montana. Estas espécies foram registradas nas outras formações também, mas de forma bem menos expressiva, o que faz delas fortes indicadoras das formações onde apresentaram alta representatividade fitossociológica. Destaca-se que a Calophyllum brasiliense foi a única espécie com alto valor de importância que apresentou comportamento restrito, sendo a segunda espécie mais importante da formação de Terras Baixas. Esta espécie é frequentemente encontrada abaixo dos 30 m (KLEIN, 1978; CARVALHO et al., 2006; GALVÃO et al., 2002; ZACARIAS, 2008), onde se situam as planícies litorâneas sujeitas às inundações (LEITE e KLEIN, 1990).

Algumas espécies que eram originalmente abundantes na floresta, conforme Klein (1978), não estavam entre as espécies com maior valor de importância, como Magnolia ovata, Copaifera trapezifolia e Nectandra lanceolata. Em uma floresta submontana, localizada em Blumenau - SC, Schorn e Galvão (2009) verificaram a ausência ou 
(a) 70

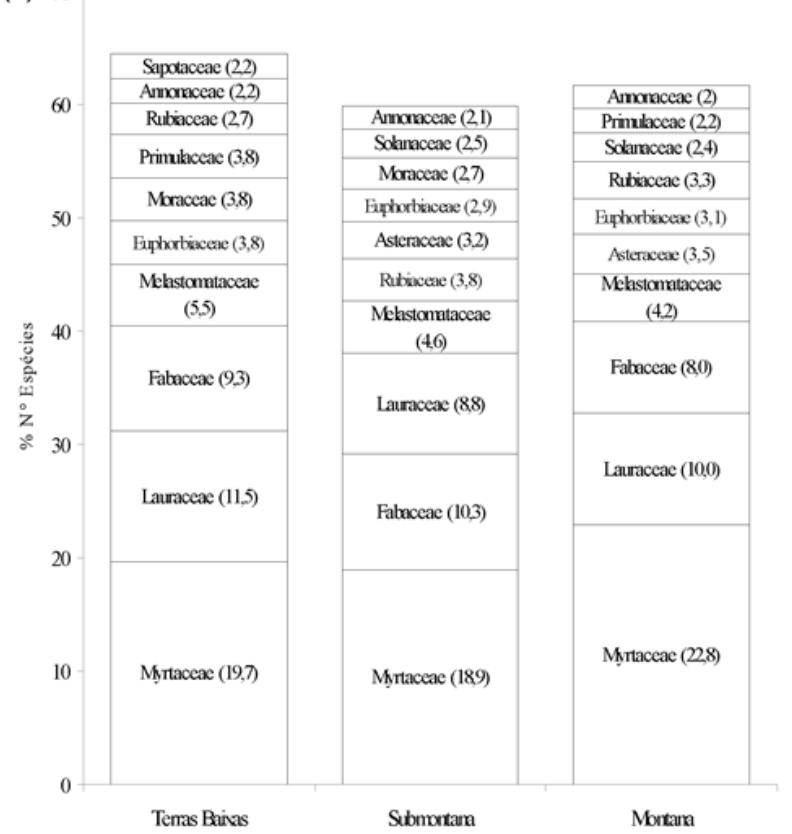

(b) 70

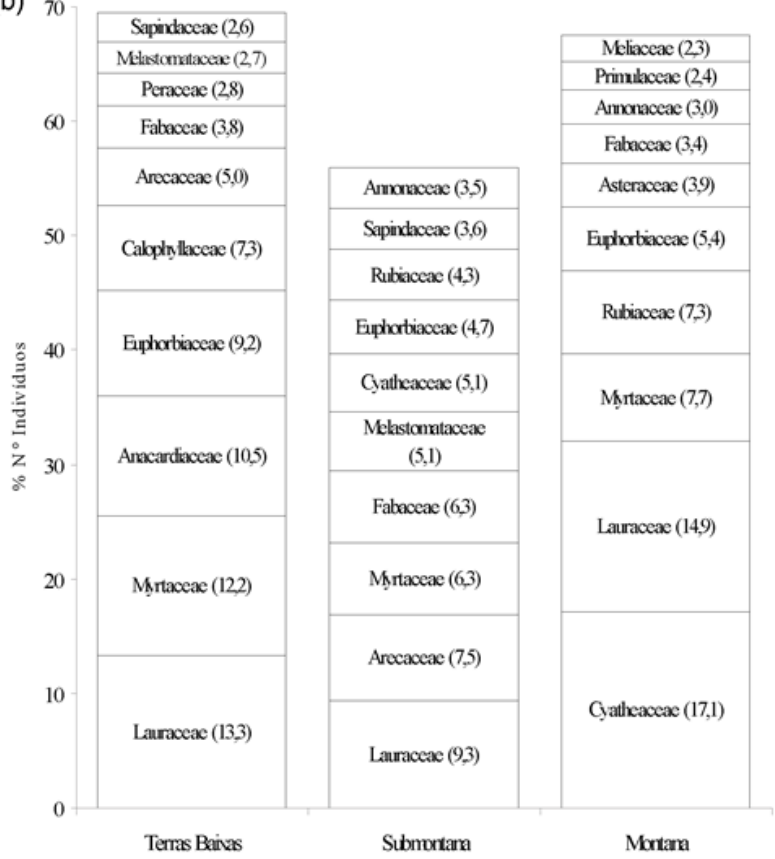

FIGURA 4: Representatividade das 10 famílias com maior número de espécies (a) e de indivíduos (b) de cada formação, na Floresta Ombrófila Densa, em Santa Catarina, sul do Brasil. Entre parênteses, tem-se o percentual do número de espécies/indivíduos das famílias.

FIGURE 4: Participation of the 10 families with the largest number of (a) species and (b) individuals of each vegetation type in the Ombrophilous Dense Forest, in Santa Catarina, southern Brazil. In brackets, the percentage of the number of species/individuals of the families.

baixa densidade de Ocotea catharinensis, Ocotea odorifera, e Cryptocarya aschersoniana. O enorme interesse pelo uso dessas espécies devido à sua madeira de boa qualidade, somada à inexistência de programas efetivos de manejo florestal, tem comprometido a sobrevivência de muitas delas (QUINET e ANDREATA, 2002).

Schorn e Galvão (2009) afirmam que, embora o processo intenso de extração madeireira tenha ocorrido a mais de 20 anos, essa atividade alterou a estrutura e a composição da floresta, afetando também a quantidade e qualidade de propágulos. Além disso, ações antrópicas são continuamente impingidas sobre os remanescentes florestais, tais como corte seletivo, roçadas e substituição da vegetação por atividades agropecuárias ou urbanas, influenciando na composição, diversidade e estrutura da floresta. Outro aspecto importante relacionado à remoção seletiva das espécies "nobres" no passado é o estabelecimento de clareiras com a abertura do dossel, favorecendo o desenvolvimento de espécies pioneiras e secundárias iniciais, tais como
Alchornea triplinervia, Caseria sylvestris, Cecropia glaziovii,Miconiacabucu e Miconiacinnamomifolia, cujo valor fitossociológico foi relativamente alto (Tabela 4). A Alchornea triplinervia foi bem representada em todas as formações, indicando que sua distribuição geográfica é bastante ampla (CARVALHO, 2006), mas que a perturbação da floresta tem promovido ainda mais sua expansão.

\section{Comparativo dos descritores estruturais da floresta}

As variáveis que apresentaram diferença significativa ao nível de $95 \%$ de probabilidade foram altura média, densidade, área basal, número de espécies e de famílias (Tabela 5). Estas diferenças estruturais entre as formações consideradas refletem as adequações das comunidades florestais às variações dos fatores abióticos ao longo do gradiente altitudinal.

Nota-se o aumento do número de indivíduos com o aumento da altitude, ocorrendo uma média de 594,4 ind.ha ${ }^{-1}$ na formação de Terras por Lacerda 
Baixas, que significativamente difere da densidade do componente arbóreo ao longo de um gradiente média de 724,46 ind.ha ${ }^{-1}$ observada na formação Montana. Ao comparar aspectos fitossociológicos altitudinal da Serra da Prata - PR, Blum (2006) de cinco fitotipias detectadas através do estudo constata, de modo geral, o aumento das densidades em função do aumento da altitude, juntamente com

TABELA 3: Lista das 20 espécies com o maior valor de importância de cada formação.

TABLE 3: List of the 20 species with the highest importance value of each vegetation type.

\begin{tabular}{|c|c|c|c|c|c|c|c|c|c|c|c|c|c|c|}
\hline \multicolumn{5}{|c|}{ Terras Baixas } & \multicolumn{5}{|c|}{ Submontana } & \multicolumn{5}{|c|}{ Montana } \\
\hline Espécie & $\begin{array}{l}\text { DR } \\
(\%)\end{array}$ & $\begin{array}{l}\text { FR } \\
(\%) \\
\end{array}$ & $\begin{array}{l}\text { DoR } \\
(\%)\end{array}$ & $\begin{array}{c}\mathrm{VI} \\
(\%)\end{array}$ & Espécie & $\begin{array}{l}\text { DR } \\
(\%)\end{array}$ & $\begin{array}{l}\mathrm{FR} \\
(\%)\end{array}$ & $\begin{array}{c}\text { DoR } \\
(\%)\end{array}$ & $\begin{array}{r}\text { VI } \\
(\%) \\
\end{array}$ & Espécie & $\begin{array}{l}\text { DR } \\
(\%) \\
\end{array}$ & $\begin{array}{l}\text { FR } \\
(\%)\end{array}$ & $\begin{array}{l}\text { DoR } \\
(\%)\end{array}$ & $\begin{array}{l}\text { VI } \\
(\%) \\
\end{array}$ \\
\hline $\begin{array}{l}\text { Tapirira } \\
\text { guianensis \#* }\end{array}$ & 10,37 & 2,01 & 16,61 & 9,66 & $\begin{array}{l}\text { Hieronyma } \\
\text { alchorneoides \# }\end{array}$ & 3,42 & 1,21 & 4,87 & 3,17 & Alsophila setosa \#* & 10,43 & 1,23 & 3,41 & 5,02 \\
\hline $\begin{array}{l}\text { Calophyllum } \\
\text { brasiliense \# }\end{array}$ & 7,25 & 1,61 & 11,99 & 6,95 & Euterpe edulis \# & 5,07 & 1,28 & 1,79 & 2,71 & Alchornea triplinervia * & 3,95 & 1,32 & 7,58 & 4,28 \\
\hline $\begin{array}{l}\text { Alchornea } \\
\text { triplinervia \#* }\end{array}$ & 7,29 & 2,01 & 6,05 & 5,12 & $\begin{array}{l}\text { Miconia } \\
\text { cinnamomifolia \# }\end{array}$ & 2,75 & 0,95 & 3,32 & 2,34 & Cyathea phalerata \# & 5,65 & 1,06 & 2,27 & 3 \\
\hline $\begin{array}{l}\text { Nectandra } \\
\text { oppositifolia } \\
\text { \#* }^{*}\end{array}$ & 3,62 & 2,01 & 4,9 & 3,51 & $\begin{array}{l}\text { Alchornea } \\
\text { triplinervia * }\end{array}$ & 1,98 & 1,26 & 3,27 & 2,17 & Psychotria vellosiana \#* & 3,83 & 1,48 & 3,35 & 2,89 \\
\hline $\begin{array}{l}\text { Syagrus } \\
\text { romanzoffiana } \\
\text { \#* }\end{array}$ & 4,25 & 1,41 & 3,59 & 3,08 & $\begin{array}{l}\text { Syagrus } \\
\text { romanzoffiana * }\end{array}$ & 2,36 & 0,95 & 2,67 & 1,99 & Ocotea catharinensis \# & 1,49 & 0,98 & 3,17 & 1,88 \\
\hline $\begin{array}{l}\text { Ocotea } \\
\text { aciphylla \# }\end{array}$ & 2,62 & 1,41 & 4,15 & 2,73 & Casearia sylvestris \# & 2,14 & 1,39 & 1,4 & 1,64 & Cabralea canjerana* & 1,43 & 1,34 & 2,13 & 1,63 \\
\hline $\begin{array}{l}\text { Aniba firmula } \\
\#\end{array}$ & 2,92 & 1,41 & 2,48 & 2,27 & Cecropia glaziovii \# & 1,64 & 1,28 & 1,6 & 1,5 & Guatteria australis \# & 1,84 & 1,21 & 1,75 & 1,6 \\
\hline $\begin{array}{l}\text { Sloanea } \\
\text { guianensis \#* }\end{array}$ & 2,25 & 1,81 & 2,61 & 2,22 & $\begin{array}{l}\text { Cabralea } \\
\text { canjerana* }\end{array}$ & 1,35 & 1,29 & 1,76 & 1,47 & $\begin{array}{l}\text { Cryptocarya } \\
\text { mandioccana \# }\end{array}$ & 1,23 & 0,86 & 2,23 & 1,44 \\
\hline $\begin{array}{l}\text { Pera glabrata } \\
\#^{*}\end{array}$ & 2,75 & 2,21 & 1,41 & 2,12 & Sloanea guianensis* & 1,56 & 0,9 & 1,88 & 1,45 & Aspidosperma australe \# & 1,34 & 0,9 & 1,49 & 1,24 \\
\hline $\begin{array}{l}\text { Myrcia } \\
\text { brasiliensis \# }\end{array}$ & 2,54 & 1,81 & 1,92 & 2,09 & Tapirira guianensis* & 1,38 & 0,56 & 2,29 & 1,41 & Vernonanthura discolor \# & 1,33 & 0,79 & 1,41 & 1,18 \\
\hline $\begin{array}{l}\text { M. } \\
\text { intermedia* }\end{array}$ & 2,29 & 1,61 & 2,25 & 2,05 & N. oppositifolia* & 1,07 & 1,06 & 1,92 & 1,35 & Ocotea elegans \# & 0,99 & 1,17 & 1,4 & 1,18 \\
\hline $\begin{array}{l}\text { Ficus } \\
\text { cestrifolia }\end{array}$ & 1,46 & 1,2 & 2,83 & 1,83 & Guapira opposita* & 1,78 & 0,98 & 1,23 & 1,33 & Bathysa australis & 1,58 & 0,67 & 1,21 & 1,15 \\
\hline $\begin{array}{l}\text { Coussapoa } \\
\text { microcarpa \# }\end{array}$ & 1,54 & 1,61 & 2,14 & 1,76 & Alsophila setosa* & 2,38 & 0,77 & 0,77 & 1,31 & Byrsonima ligustrifolia & 1,29 & 0,88 & 1,23 & 1,13 \\
\hline Ilex theezans \# & 1,08 & 1,81 & 1,02 & 1,3 & $\begin{array}{l}\text { Matayba } \\
\text { intermedia* }\end{array}$ & 1,15 & 1,28 & 1,31 & 1,25 & Clethra scabra* & 1,39 & 0,69 & 1,27 & 1,12 \\
\hline $\begin{array}{l}\text { Psidium } \\
\text { cattleianum \# }\end{array}$ & 1,83 & 1 & 1,03 & 1,29 & P. vellosiana* & 1,58 & 0,88 & 1,17 & 1,21 & Cedrela fissilis* & 0,73 & 1,09 & 1,52 & 1,11 \\
\hline $\begin{array}{l}\text { Andira } \\
\text { fraxinifolia \# }\end{array}$ & 1,21 & 1,2 & 1,24 & 1,22 & Virola bicuhyba \# & 1,03 & 0,96 & 1,59 & 1,19 & Ocotea odorifera \# & 1,04 & 0,9 & 1,22 & 1,05 \\
\hline $\begin{array}{l}\text { Myrcia } \\
\text { pubipetala \# }\end{array}$ & 1,17 & 1,61 & 0,67 & 1,15 & Cedrela fissilis \#* & 0,97 & 1,23 & 1,31 & 1,17 & Guapira opposita* & 1,12 & 0,84 & 1,04 & 1 \\
\hline $\begin{array}{l}\text { Garcinia } \\
\text { gardneriana \# }\end{array}$ & 1,08 & 1,81 & 0,54 & 1,14 & Cupania vernalis & 1,5 & 0,85 & 1,09 & 1,15 & $\begin{array}{l}\text { Cryptocarya } \\
\text { aschersoniana \# }\end{array}$ & 0,83 & 0,58 & 1,47 & 0,96 \\
\hline $\begin{array}{l}\text { Aparisthmium } \\
\text { cordatum \# }\end{array}$ & 1,46 & 1,2 & 0,59 & 1,08 & Clethra scabra* & 1,7 & 0,59 & 1,07 & 1,12 & Lamanonia ternata \# & 1,05 & 0,73 & 1,02 & 0,93 \\
\hline $\begin{array}{l}\text { Protium } \\
\text { kleinii }\end{array}$ & 0,79 & 1,2 & 1,1 & 1,03 & Pera glabrata* & 1,39 & 0,75 & 1,12 & 1,09 & Ocotea puberula & 0,96 & 0,54 & 1,2 & 0,9 \\
\hline Subtotal & 59,77 & 31,95 & 69,12 & 53,6 & Subtotal & 38,2 & 20,42 & 37,43 & 32,02 & Subtotal & 43,5 & 19,26 & 41,37 & 34,69 \\
\hline $\begin{array}{l}\text { Demais } \\
\text { espécies }\end{array}$ & 40,23 & 68,05 & 30,88 & 46,4 & Demais espécies & 61,8 & 79,58 & 62,57 & 67,98 & Demais espécies & 56,5 & 80,74 & 58,63 & 65,31 \\
\hline
\end{tabular}

Em que: $\mathrm{DR}=$ densidade relativa (\%); $\mathrm{FR}=$ frequência relativa $(\%) ;$ DoR $=$ dominância relativa $(\%)$; VI = valor de importância; \# Espécies com resultados significativos $(\mathrm{p}<0,05)$ apontadas pela análise de espécies indicadoras (ISA);

* Espécies comuns entre as formações. 
TABELA 4: Teste de Tukey-Kramer para comparação de médias entre as três formações com base nos descritores estruturais do compartimento arbóreo (DAP $\geq 10 \mathrm{~cm}$ ).

TABLE 4: Tukey-Kramer test to compare means between the three vegetation types based on structural descriptors of the tree/shrub component $(\mathrm{DBH} \geq 10 \mathrm{~cm})$.

\begin{tabular}{lccccc}
\hline \multicolumn{1}{c}{ Variáveis } & Terras Baixas & Submontana & \multicolumn{2}{c}{ Montana } & \multicolumn{2}{c}{ ANOVA } \\
\hline DAP médio $(\mathrm{cm})$ & $\mathrm{UA}=11$ & $\mathrm{UA}=107$ & $\mathrm{UA}=79$ & $\mathrm{~F}$ & $\mathrm{p}$ \\
DAP máximo $(\mathrm{cm})$ & $19,03 \pm 2,02 \mathrm{a}$ & $17,86 \pm 2,12 \mathrm{a}$ & $18,31 \pm 2,53 \mathrm{a}$ & 17,936 & 0,167 \\
H média $(\mathrm{m})$ & $11,59 \pm 10,19 \mathrm{a}$ & $62,14 \pm 22,11 \mathrm{a}$ & $69,61 \pm 28,34 \mathrm{a}$ & 25,049 & 0,082 \\
H média superior $(\mathrm{m})$ & $17,13 \pm 2,37 \mathrm{a}$ & $11,24 \pm 1,6 \mathrm{a}$ & $10,08 \pm 1,26 \mathrm{~b}$ & 15,74 & $<0,0001$ \\
H máximo $(\mathrm{m})$ & $22 \pm 4,8 \mathrm{a}$ & $23,22 \pm 4,61 \mathrm{a}$ & $16,45 \pm 2,53 \mathrm{a}$ & 2,558 & 0,0781 \\
Densidade $\left(\right.$ ind.ha $\left.^{-1}\right)$ & $594,4 \pm 151,93 \mathrm{a}$ & $663,08 \pm 132,78 \mathrm{a}$ & $724,46 \pm 192,78 \mathrm{~b}$ & 51,321 & 0,007 \\
Área basal $\left(\mathrm{m}^{2} \cdot \mathrm{ha}^{-1}\right)$ & $21,7 \pm 5,69 \mathrm{ab}$ & $22,66 \pm 6,68 \mathrm{a}$ & $25,26 \pm 7,86 \mathrm{~b}$ & 34,611 & 0,0323 \\
N. Espécies & $42,45 \pm 15,39 \mathrm{a}$ & $54,36 \pm 14,28 \mathrm{~b}$ & $57,3 \pm 12,9 \mathrm{~b}$ & 57,519 & 0,0041 \\
N. Famílias & $24,55 \pm 6,06 \mathrm{a}$ & $28,79 \pm 5,12 \mathrm{~b}$ & $27,96 \pm 5,24 \mathrm{ab}$ & 34,491 & 0,0327 \\
\hline
\end{tabular}

Em que: $\mathrm{UA}=$ número de unidades amostrais; $\mathrm{DAP}=$ diâmetro a altura do peito, medido a $1,30 \mathrm{~m}$ do solo; $\mathrm{H}=$ altura; $\mathrm{N}$. Espécies = número de espécies; N. Famílias = número de famílias. Letras distintas entre linhas demonstram diferenças estatísticas entre as três formações florestais pelo teste de Tukey-Kramer a 5 \% de significância.

a consequente redução da profundidade do solo. Paciencia (2008) estudou o grupo das pteridófitas e pôde perceber a mesma tendência entre o número de indivíduos e o gradiente altitudinal avaliado de 50 a $1.400 \mathrm{~m}$, em comunidades florestais paranaenses. Acompanhando o aumento da densidade, a área basal tendeu a ser maior nas áreas mais elevadas do presente estudo, o que foi verificado também (2001) no município de Ubatuba - SP. Blum (2006) não observou variação significativa da área basal em função da altitude.

A riqueza de espécies foi em média menor nas florestas de terras baixas, diferindo de maneira significativa das formações Submontana e Montana, possivelmente influenciada pelas condições de sítio mais seletivas nas terras baixas (solos hidromórficos, baixo $\mathrm{pH}$ ). Ao comparar o número de espécies e famílias entre uma área de planície e uma floresta submontana, no município de Guaraqueçaba - PR, Zacarias (2008) verificou que a riqueza de espécies das encostas é superior. Avaliando 87 florestas neotropicais situadas em 25 países, Gentry (1988) apontou um decréscimo da riqueza com o aumento da altitude, tendência esta observada também por Vásquez \& Givnish (1998) e Blum (2006). Lacerda (2001) observou maior diversidade entre 300 e 600 $\mathrm{m}$.

A altura média apresentou redução com o avanço aos patamares superiores, havendo diferença significativa entre a formação Montana com as florestas situadas abaixo de $500 \mathrm{~m}$. É provável que a ocorrência da neblina e a diminuição da temperatura em altitudes mais elevadas sejam os fatores mais preponderantes na limitação do crescimento das árvores (LACERDA, 2001), enquanto Blum (2006) constatou que com a elevação da altitude, tanto a altura média como o diâmetro médio diminuem. Zacarias (2008) observou diferença significativa da altura entre duas florestas da formação aluvial com condições edáficas distintas, fato que aponta também a influência de fatores edáficos na altura média das árvores das florestas.

\section{CONCLUSÕES}

O componente arbóreo-arbustivo da Floresta Ombrófila Densa de Santa Catarina apresenta expressiva diversidade florística. No entanto, encontra-se constituída majoritariamente por florestas secundárias dominadas por espécies de áreas perturbadas como Alchornea triplinervia, Caseria sylvestris, Cecropia glaziovii, Miconia cabucu e Miconia cinnamomifolia, ao mesmo tempo em que espécies que determinavam a estrutura original da floresta agora são encontradas com baixa representatividade. A altitude demonstrou ser um importante fator condicionante na variação florística-estrutural da floresta, observando-se a 
formação de basicamente três grupos dentro do gradiente altitudinal estudado, havendo diferença significativa entre os seus descritores estruturais e espécies preferenciais associadas. Sugere-se a realização de estudos complementares, como a análise da regeneração, para extrair informações mais conclusivas sobre a dinâmica sucessional e a permanência das espécies na floresta.

\section{AGRADECIMENTOS}

Os autores agradecem a FAPESC Fundação de Amparo à Pesquisa e Inovação do Estado de Santa Catarina pelo financiamento do projeto IFFSC.

\section{REFERÊNCIAS BIBLIOGRÁFICAS}

AGUIRRE, G.H. Caracterização da vegetação arbustivo-arbórea de fragmentos de Floresta Ombrófila Densa Montana. 2008. Dissertação (Mestrado) - Universidade Estadual de Campinas, Campinas.

AMARAL JÚNIOR, A. Flora Ilustrada Catarinense: Eritroxiláceas. Itajaí: Herbário Barbosa Rodrigues, 64 p., 1980.

AYRES, M. et al. Bioestat: aplicações estatísticas nas áreas das Ciências Biomédicas. Versão 5.0. Belém, Pará: Sociedade Civil Mamirauá, MCTCNPq, 324 p., 2007.

BARROS, F. Análise multivariada da distribuição geográfica de espécies de orquídeas dos campos rupestres do Brasil. 1998. 206 p. Tese (Doutorado) - Universidade Estadual de Campinas, Campinas.

BEZERRA NETO, F. V. B. et al. Descritores quantitativos na estimativa da divergência genética entre genótipos de Mamoneira utilizando análises multivariadas. Revista Ciência Agronômica, Ceará, v. 41, n. 02, p. 294-299, 2010.

BLUM, C.T. A Floresta Ombrófila Densa na Serra da Prata, Parque Nacional Saint-Hilaire/Lange, PR - Caracterização florística, fitossociológica e ambiental de um gradiente altitudinal. 2006. Dissertação (Mestrado em Engenharia Florestal) Curso de Pós-Graduação em Engenharia Florestal, UFPR, Curitiba.

BLUM, C. T.; RODERJAN, C. V. Espécies indicadoras em um gradiente da Floresta Ombrófila Densa na Serra da Prata, Paraná, Brasil. Revista Brasileira de Biociências, Porto Alegre, v. 5, n. 2, p. $873-875,2007$.

BROWER, J.E.; ZAR, J.H. Field \& laboratory methods for general ecology. W.C. Brown Publishers, Boston, 1984.

CARVALHO, P. E. R. Espécies Arbóreas Brasileiras. Brasília: Embrapa Informação Tecnológica; Colombo, PR : Embrapa Florestas, v. 2, 2006.

CARVALHO, L. M. T.; FONTES, M. A. L.; OLIVEIRA-FILHO, A. T. Tree species distribution in canopy gaps and mature forest in an area of cloud forest of the Ibitipoca Range, south-eastern Brazil. Plant Ecology, v. 149, p. 9 - 22, 2000.

CARVALHO, F. A. et al. Estrutura da comunidade arbórea da floresta atlântica de baixada periodicamente inundada na Rebio de Poço das Antas, RJ. Rodriguesia, Rio de Janeiro, v. 5, p. $503-518,2006$.

CARVALHO, F. A.; NASCIMENTO, M. T.; OLIVEIRA FILHO, A. T. Composição, riqueza e heterogeneidade da flora arbórea da Bacia do Rio São João, RJ, Brasil. Acta Botânica Brasílica, v. 22, n. 4, p. 929- 940, 2008.

CATHARINO, E.L.M. et al. Aspectos da composição e diversidade dos componentes arbóreo das florestas da Reserva Florestal do Morro Grande, Cotia, SP. Biota Neotropica, São Paulo, v. 6, n. 2, p. 1 - 28, 2006.

CERVI, A. C.; HATSBACH, G. G.; LINSIGEN, L. V. Composição florística de um trecho de Floresta Ombrófila Densa de Terras Baixas (Floresta Atlântica) na Reserva Ecológica de Sapitanduva (Morretes, Paraná, Brasil). Fontqueria, Madri, Espanha, v. 55, n. 52, p. 423 - 438, 2007.

DUFRENÊ, M.; LEGENDRE, P. Species assemblages and indicator species: the need for a flexible asymmetrical approah. Ecological Monograhs, Washington, v. 67, n. 3, p. 345 - 366, 1997.

FERNANDES, C. R. Floresta Atlântica: Reserva da Biosfera. 20 ed. Curitiba: Tempo Integral, 2003. FORZZA, R.C. et al. Introdução. in Lista de Espécies da Flora do Brasil. Jardim Botânico do Rio de Janeiro, 2010.

GALVÃO, F. et al. Composição florística e fitossociologia de caxetais do litoral do Estado do Paraná. Floresta, Curitiba -PR, v. 32, n. 1, p. 17-39, 2002.

GAUCH-JUNIOR, H.G. Mulltivariate Analysis in Community Ecology. Cambridge. Cambridge University Press, 1982.

GENTRY, A.H. Changes in plant community diversity and floristic composition on environment and geographical gradients. Annals of the Missouri 
Garden, v. 75, n. 1, p. 1 - 34, 1988.

GUEDES-BRUNI, R. R. et al. Composição florística e estrutura de trecho de Floresta Ombrófila Densa Atlântica aluvial na Reserva Biológica de Poço Das Antas, Silva Jardim, Rio De Janeiro, Brasil. Rodriguesia, Rio de Janeiro v. 57, n. 3, p. 413 428, 2006.

HAMMER, O.; HARPER, D.A.T.; RYAN, P. D. PAST: Paleontological Statistics Software Package for Education and Data Analysis. Palaeontologia Electronica 4 (1): 9pp. Disponível em: <http:// palaeo-electronica.org/2001_1/past/issue1_01. $\mathrm{htm}>$. Acesso em: 2001.

HILL, M. O.; GAUCH Jr., H. G. Detrended correspondence analysis, an improved ordination technique.Vegetatio, v. 42, p. 47 - 58, 1980.

IBGE - Instituto Brasileiro de Geografia e Estatística. Manual técnico da vegetação brasileira. Rio de Janeiro, 92p. (Manuais Técnicos em Geociências, 1), 1992.

KLEIN, R.M. Mapa fitogeográfico do estado de Santa Catarina. Herbário Barbosa Rodrigues, Itajaí: UFSC, 24p, 1978.

Instrução normativa $\mathrm{n}^{\circ} \mathbf{6}$, de 23 de setembro de 2008. http://portal.saude.gov.br/portal/ arquivos/ pdf/MMA_IN_N_6.pdf (acesso em: 15/03/2012).

LACERDA, M.S. Composição florística e estrutura da comunidade arbórea num gradiente altitudinal da Mata Atlântica. 2001. Tese (Doutorado em Biologia) - Instituto de Biologia, Universidade Estadual de Campinas, Campinas.

LANDRUM, L.R. A Monograph of the Genus Myrceugenia (Myrtaceae). Flora Neotropica, v. 29, p.1-135, 1981.

LEITE, P.F.; KLEIN, R.M. Vegetação. In Geografia do Brasil: Região Sul. Instituto Brasileiro de Geografia e Estatística, Rio de Janeiro, v. 2, p.113-150, 1990.

MCCUNE, B.; MEFFORD, M.J. PC-ORD, Multivariate analysis of ecological data, Version 6. MjM Software Design. Gleneden Beach. Oregon. USA, 2011.

MEDEIROS, R. M. Estratificação volumétrica e crescimento em uma floresta ombrófila densa, município de Almeirim, estado do Pará. 2008. 87p. Dissertação (Mestrado em Ciência Florestal) Universidade Federal de Viçosa, Viçosa.

MORI, S.A. et al. Ecological importance of Myrtaceae in an Eastern Brazilian wet forest. Biotropica, v. 15, n. 1, p. 68 - 79, 1983.

MUELLER-DOMBOIS，D.; ELLENBERG， H. Aims and methods of vegetation ecology. Wiley.
New York, 1974.

NEGRELLE，R. R. B. Composição florística e estrutura vertical de um trecho de Floresta Ombrófila Densa de Planície Quaternária. Hoehnea, v. 33, n. 3, p. 261 - 289, 2006.

NIMER, E. Climatologia do Brasil. Rio de Janeiro: IBGE. 422p, 1979.

OLIVEIRA-FILHO, A.T.; FONTES, M.A.L. Patterns of floristic differentiation among Atlantic Forests in Southeastern Brazil and the influence of climate. Biotropica, v. 32, p. 793 - 810, 2000.

PACIENCIA, M. L. B. Diversidade de Pteridófitas em gradientes de altitude na Mata Atlântica do Estado do Paraná, Brasil. 2008. 230p. Tese (Doutorado) - Universidade de São Paulo, São Paulo.

PAULA,A. Florística e fitossociologia de um trecho de floresta ombrófila densa das terras baixas na Reserva Biológica de Sooretama, Linhares - ES. 2006. 91f. Tese (Doutorado em Ecologia e Recursos Naturais) - PPGERN, Universidade Federal de São Carlos, São Carlos, 2006.

PEIXOTO, A.L.; REITZ, R.; GUIMARÃES, E.F. 2001. Monimiáceas. p. 6-9. In: Reitz, R. (ed.). Flora Ilustrada Catarinense. Parte I. Herbário Barbosa Rodrigues, Itajaí.

PIRES, P. T. L.; ZILLI, A. L.; BLUM, C. T. (Coord.). Atlas da Floresta Atlântica no Paraná - Área de abrangência do Programa Proteção da Floresta Atlântica. Curitiba: SEMA/Programa Proteção da Floresta Atlântica - Pró-Atlântica, 104 p., 2005.

QUINET, A.; ANDREATA, R. H. P. Lauraceae Jussieu na Reserva Ecológica de Macaé de Cima, município de Nova Friburgo, Rio de Janeiro, Brasil. Rodriguesia, v. 53, n. 82, p. 59 - 121, 2002.

REIS, A. et al. Demografia de Euterpe edulis Martius (Arecaceae) em uma floresta ombrófila densa montana, em Blumenau (SC). Sellowia, v. 45 - 48, p. 13 - 45, 1996.

REITZ, P.R. Flora Ilustrada Catarinense: Sapotáceas. Itajaí - SC, 1968. 72p.

ROCHELLE, A. L. C. Heterogeneidade ambiental, diversidade e estrutura da comunidade arbórea de um trecho da Floresta Ombrófila Densa Atlântica. 2008. 126p. Dissertação (Mestrado em Biologia Vegetal) - Universidade Estadual de Campinas, Campinas.

SAR. Secretaria de Agricultura e Abastecimento do Estado de Santa Catarina. Inventário Florístico Florestal de Santa Catarina. Relatório do Projeto Piloto. Florianópolis. 2005 (mimeo), 170 p.

SCHORN, L. A.; GALVÃO, F. Dinâmica do estrato 
arbóreo em três estádios sucessionais de uma floresta ombrófila densa em Blumenau, SC. Cerne, Lavras, v. 15, n. 2, p. 221- 235, 2009.

SDM - Secretaria de Estado do Desenvolvimento Urbano Social e Meio Ambiente de Santa Catarina.

Bacias Hidrográficas do Estado de Santa Catarina: diagnóstico geral. Florianópolis, 163 p., 1997.

SILVA, R. K. S. Fitossociologia do componente arbóreo em áreas ciliares e de nascentes de um fragmento de floresta ombrófila densa de terras baixas, em Sirinhaém, Pernambuco. 2009. 80p. Dissertação (Mestrado em Ciências Florestais) Universidade Federal Rural de Pernambuco, Recife. SIMINSKI A. et al. Secondary Forest Succession in the Mata Atlantica, Brazil: Floristic and Phytosociological Trends. ISRN Ecology. v. 2011, p. 1-19, 2011.

SOBRAL, M. A família das Myrtaceae no Rio Grande do Sul. São Leopoldo, Unisinos, 215p., 2003.

SOUZA, A. L. et al. Análises multivariadas para manejo de floresta natural na Reserva Florestal de Linhares, Espírito Santo: análises de agrupamento e discriminante. Revista Árvore, Viçosa, v. 14, n. 2 , p. $85-101,1990$.

SOUZAA.L. et al. Dinâmica da regeneração natural em uma Floresta Ombrófila Densa secundária, após corte de cipós, reserva natural da Companhia Vale do Rio Doce S.A., Estado do Espírito Santo, Brasil. Revista Árvore, Viçosa, v. 26, n. 4, p. 411- 419, 2002.

TABARELLI, M.; MANTOVANI, W. A riqueza de espécies arbóreas na floresta atlântica de encosta no estado de São Paulo (Brasil). Revista Brasileira de
Botânica, v. 1, n. 1, p. 217- 223, 1999.

VALENTIN, J. L. Ecologia numérica: uma introdução à análise multivariada de dados ecológicos. Rio de Janeiro: Interciência. 117 p., 2000.

VÁZQUEZ, J.A.; GIVNISH, T.J. Altitudinal gradients in tropical Forest composition, structure, and diversity in the Sierra de Manantlán. Journal of Ecology, v. 86, p. 999 - 1020, 1998.

VELOSO, H. P.; KLEIN, R. M. As comunidades e associações vegetais da mata pluvial do sul do Brasil. VI. Agrupamentos arbóreos dos confra-fortes da Serra Geral Situados ao Sul da Costa Catarinense e ao Norte da Costa Sul-Riograndense. Sellowia, v. 20, p. $127-180,1968$ b.

VIBRANS, A.C. et al. How much remains of the Brazilian Atlantic forest in the state of Santa Catarina? Assessing the accuracy of forest cover maps using ground data from the Santa Catarina Forest and Floristic Inventory. Remote Sensing of Environment, Colombo, 2012.

VIBRANS, A.C. et al. Inventário florístico florestal de Santa Catarina (IFFSC): aspectos metodológicos e operacionais. Pesquisa Florestal Brasileira, v. 30, n. 64, p. 291- 302, 2010.

VIBRANS, A. C. et al. Structure of mixed ombrophyllous forests with Araucaria angustifolia (Araucariaceae) under external stress in Southern Brazil. Revista Biologia Tropical, v. 59, n. 3, p.1371-1387, 2011.

ZACARIAS, R. R. O componente arbóreo de dois trechos de Floresta Ombrófila Densa Aluvial em solos hidromórficos, Guaraqueçaba, Paraná. 2008. Dissertação (Mestrado) - Universidade Federal do Paraná, Curitiba. 